\title{
A General Model for Describing the Performance of Brushless Doubly-Fed Induction Machines
}

\author{
S. M. Allam*a, A. M. Azmyb, and M. A. El-Khazendarc \\ a Electrical Power and Machines Department, Faculty of Engineering, Tanta University, Tanta, Egypt

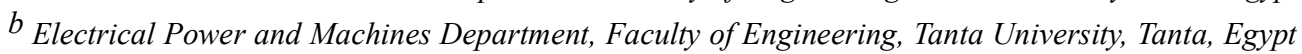 \\ ${ }^{c}$ Electrical Power and Machines Department, Faculty of Engineering, Tanta University, Tanta, Egypt
}

Received 27 May 2009; accepted 19 June 2010

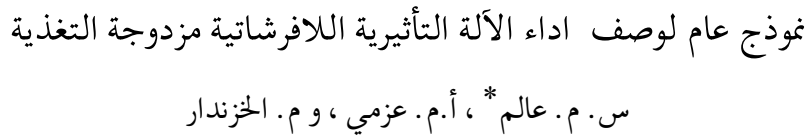

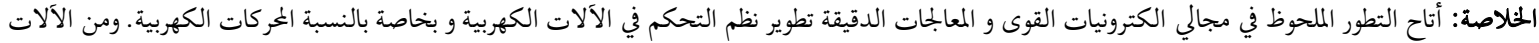

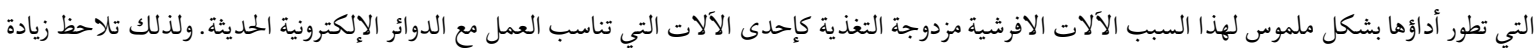

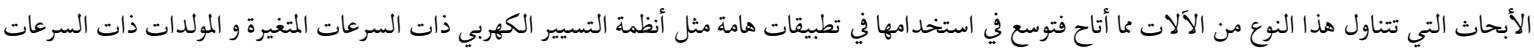

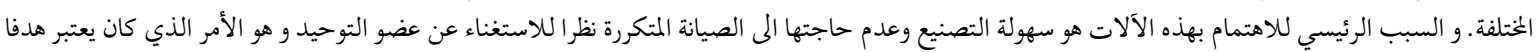

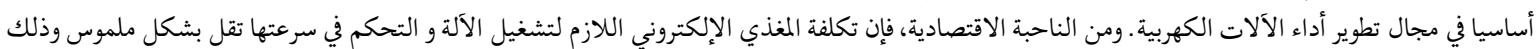

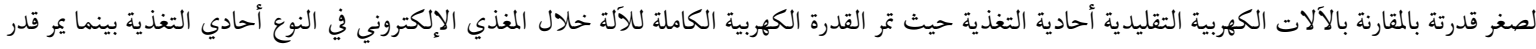

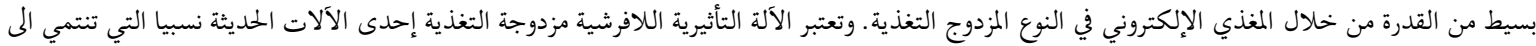

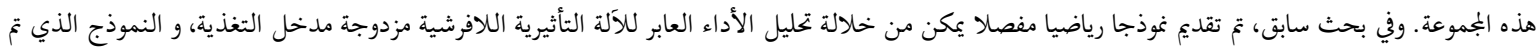

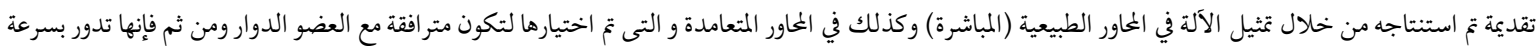

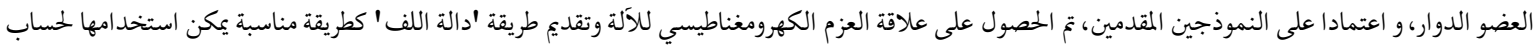

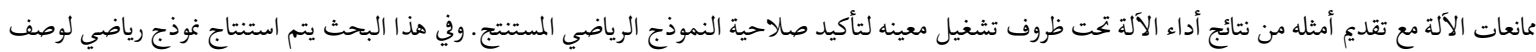

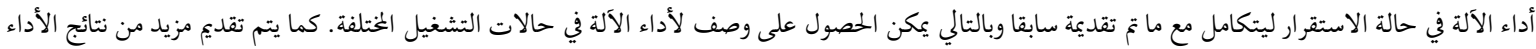

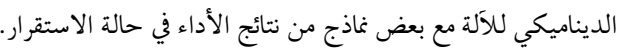

المفردات المفتاحية : الآلات اللافرشاتية مزدوجة التغذية، تحليل الأداء العابر، تحليل حالة الاستقرار، النظرية العامة للآلات، الآلات الحثية، انظمة التسيير الكهربي ذات السرعات المتغيرة.
\end{abstract}

\begin{abstract}
This paper presents a generalized model, by which the dynamic and steady-state behaviour of the Brushless Doubly-Fed Induction Machine (BDFIM) can be precisely predicted. The investigated doubly-fed machine has two sets of three-phase stator windings with different pole numbers. The rotor is a squirrel-cage type with a simple modification in order to support the two air-gap rotating fields that are produced by the stator windings and have different pole numbers. The machine model is derived in the qdo-axis variables. The qdoaxes are attached to rotor and hence, it rotates at the rotor speed $\left(\omega_{\mathrm{m}}\right)$. The electromagnetic torque expression is also obtained based on the presented model. The winding function method is applied as a convenient approach that can be used for machine-winding inductances calculations. Sample case studies are introduced to examine the performance of the proposed model in both steady-state and dynamic conditions.
\end{abstract}

Keywords: Brushless doubly-fed machine, Dynamic modelling, Steady-state modelling, Generalized theory, Induction machine, Self-cascaded, Speed control, Variable speed drives

*Corresponding author's e-mail: sm allam@hotmail.com 


\section{Nomenclature}

$\begin{array}{lll}\mathrm{B}, \mathrm{J} & : & \text { Viscous coefficient and rotor inertia respectively. } \\ \mathrm{i}_{\mathrm{rk}} & : & \text { Rotor loop current. } \\ \mathrm{N}_{\mathrm{k}} & : & \text { Turns per phase of either stator windings. } \\ \mathrm{p} & : & \text { The differential operator "d/dt". } \\ \mathrm{P}_{\mathrm{k}} & : & \text { Pole-pairs of either stator windings. } \\ \mathrm{R}, l & : & \text { Rotor radius and axial length respectively. } \\ \mathrm{r}_{\mathrm{sk}} & : & \text { Per-phase stator resistance. } \\ \mathrm{T}_{\mathrm{L}}, \mathrm{T}_{\mathrm{em}} & : & \text { Load and electromagnetic developed torque respectively. } \\ \mathrm{i}_{\mathrm{sk}}, \mathrm{v}_{\mathrm{sk}} & : & \text { Stator current and voltage respectively. } \\ \mu_{\mathrm{o}} & : & \text { Permeability for vacuum. } \\ \theta_{\mathrm{m}} & : & \text { Rotor mechanical angular position with respect to phase (a) reference axis of the two sets of stator } \\ \theta & & \text { Windings. } \\ \mathrm{g}^{-1}\left(\theta_{\mathrm{m}} \theta\right): & \text { The inverse air-gap function. } \\ \mathrm{N}_{1}\left(\theta_{\mathrm{m}} \theta\right): & \text { The winding function of winding (i). } \\ \mathrm{L}_{l k} & : & \text { Stator leakage inductance. } \\ \mathrm{L}_{\mathrm{mk}} & : & \text { Stator magnetizing inductance. } \\ \mathrm{M}_{\mathrm{r}} & : & \text { Mutual inductance between two rotor loops. } \\ \mathrm{L}_{\mathrm{mr}} & : & \text { Rotor loop magnetizing inductance. } \\ \omega_{\mathrm{m}} & : & \text { Mechanical rotor speed in rad./sec. } \\ \omega_{\mathrm{ek}} & : & \text { Stator electrical frequency in rad./sec. } \\ \mathrm{r}_{\mathrm{b}}, \mathrm{L}_{\mathrm{b}}: & \text { Rotor bar resistance and leakage inductance respectively. } \\ \mathrm{r}_{\mathrm{e}}, \mathrm{L}_{\mathrm{e}} \quad: & \text { End ring segment resistance and leakage inductance respectively. }\end{array}$

\section{Introduction}

SQUIRREL-cage induction motors are the most widely used motors in AC-drive applications. This is attributed to their ruggedness, low cost, and few maintenance requirements. The number of industrial applications, which utilize AC adjustable speed drives (ASDs), is increasing rapidly. The primarily reason for this development is the significant advent of power electronics. The main disadvantage of using singly-fed machines for ASDs is the need for large and expensive power conditioning units that should withstand the full motor power. This increases both the capital cost and the harmonic current pollution of the overall system (Li et al. 1991). The Brushless Doubly-Fed Induction Machines (BDFIMs) shows a great promise in reducing the rating of power electronic converters needed for ASDs application (Boger et al. 1995). The BDFIM represents a development of self-cascaded machines with two three-phase stator windings having different number of poles accommodated in a single machine frame. In addition, it is required to introduce a modification to the cage rotor structure (Boger et al. 1996; Boger and Wallace, 1995; Zaiping et al. 1998 and Wing et al. 2002).

In a BDFIM, the rotor structure determines the magnetic coupling between the two stator windings, which in turn determines the machine behaviour (Wang et al. 2002). BDFIM is a special form of slip recovery machines that reduce the capacity of the required inverter to be used if the required speed-control range is limited ( $(\mathrm{Li}$ et al. 1991; Boger et al. 1995; Boger et al. 1996; Boger et al. 1996; Boger and Wallace, 1995; Zaiping et al. 1998; Wing et al. 2002 and Wuilliamson et al. 1997). This will lead to a significant reduction in the drive cost. Owing to its brushless property, the BDFIM is mechanically robust and reliable. It is found that the BDFIM has the ability to provide precise speed control and good power factor with reduced converter capacity, as low as $25 \%$ of the machine rating (Boger et al. and Boger and Wallace, 1995). A further advantage of the BDFIM is derived from the fact that the power electronic converters do not process the bulk power entering or leaving the machine directly.

The dynamic model of Brushless Doubly-Fed Machines (BDFMs) was first presented in (Li et al. 1991). However, the presented model is based on a special configuration of both stator and rotor winding connections. The configurations of both stator and rotor appear to be complex compared to conventional induction machine. The dynamic model introduced in ( $\mathrm{Li}$ et al. 1991), has addressed the $3 / 1$ (power winding to control winding pole-pair numbers) exclusively. An extended model, which is appropriate for any number of pole-pairs, was introduced in (Boger et al. 1995). However, the structure of the BDFM used is similar to that used in (Li et al. 1991). The main problem of these models is the complicated structure of both stator and rotor windings that these models based upon. 
A new model based on a dual stator winding induction machine is presented in (Munoz and Lipo, 2000). The two-stator windings are simultaneously fed from two independent variable frequency power supplies. This results in increasing the capital cost of the overall system.

The aim of this paper is to present a generalized model valid for predicting the dynamic and steady-state performance of BDFIMs under different loading conditions. In addition, the paper aims at investigating the possibility of simpler structure of the BDFIM than that used before. The investigated BDFIM consists of a simply modified squirrel-cage rotor and a stator with two separate windings wound for a dissimilar number of poles. Each stator winding is fed from an independent power supply. Only one of the two stator windings is fed from a variable-frequency variable-voltage inverter.

\section{System Description}

Figure 1 shows the schematic diagram of the investigated BDFIM. There are two three-phase windings with different number of poles, in order to avoid magnetic mutual coupling, placed in the stator slots (Li et al. 1991). These windings are simultaneously fed from two independent power supplies and each one produces a separate torque component. One set of stator windings is called the power windings; through which full machine power must pass, and is fed directly from a constant voltage constant frequency power supply. The other set is called the control windings, through which partial controlled power passes, and is fed from a variable voltage variable frequency power supply.

The rotor is a squirrel-cage type with a simple modification in its structure to support the two air-gap rotating fields that have different pole numbers produced by the two-sets of stator windings (Wang et al. 2002). In (Williamson et al. 1997), it is stated that the essential requirement for brushless doubly-fed machine action is that the frequency and distribution of currents induced in the rotor by the first air-gap field match that induced by the second. The two stator windings will be then coupled via the rotor, even though they have different pole numbers and may be excited at different frequencies. This implies that the number of rotor bars should be equal to the summation of pole-pair numbers of both stator windings. Thus, the number of rotor bars will be small for any realistic combination of pole-pair numbers which results in a very high-referred rotor leakage reactance (Willaimson et al. 1997)

Therefore, more work has been done to increase the number of rotor slots and distribute each bar between several slots. However, all ways used in rotor bars arrangements are not easily fabricated. Furthermore, the cost of this type of machines is high since both stator and rotor have to be redesigned.

In this paper, a very simple modification in the rotor cage is introduced. The rotor bars are divided into number of groups that equal the required number of rotor bars

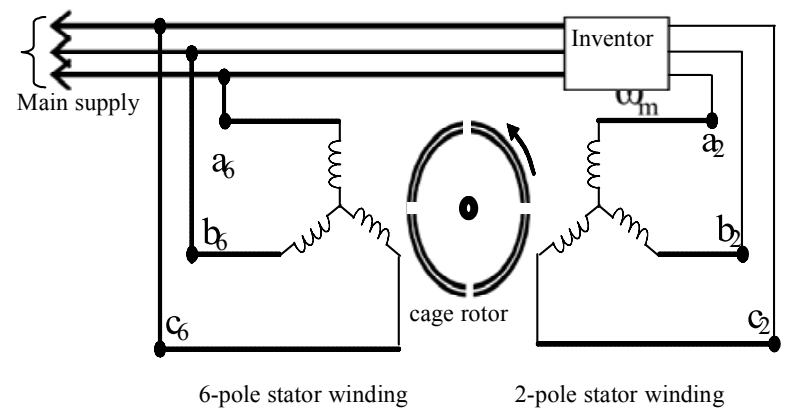

Figure 1. Schematic diagram of the BDFIM

(summation of pole-pairs of the two-stator windings). Separating each group from the others can be easily done at one side only of the two end rings. This means that one end ring is divided into a number of sections; each connecting a number of bars, while the other end ring connects all rotor bars. For 6-pole and 2-pole stator windings, the number of required rotor bars or groups equals four. Therefore, one side of the end rings should be divided into four groups or sections. A schematic diagram of the BDFIM is shown in Fig. 1.

$$
\mathrm{L}_{\mathrm{ij}}=\mu_{\mathrm{o}} \mathrm{R} \ell \int_{0}^{2 \pi} \mathrm{g}^{-1}\left(\theta_{\mathrm{m}}, \theta\right) \mathrm{N}_{\mathrm{i}}\left(\theta_{\mathrm{m}}, \theta\right) \mathrm{N}_{\mathrm{j}}\left(\theta_{\mathrm{m}}, \theta\right) \mathrm{d} \theta(1)
$$

\section{Inductance Calculations}

The machine-winding inductances can be calculated by a particular convenient approach called winding functions method (Liang et al. and $\mathrm{Xu}$ et al. 1991). The winding function is defined as the spatial distribution of $M M F$ due to a unit current flowing in the winding. According to this method, the machine inductances are calculated by an integral expression representing the placement of winding turns along the air-gap periphery. This method is particularly convenient for the analysis of unusual machines since it assumes no symmetry in the placement of any motor coil in the slots (Xu et al. 1991). According to the winding function theory, the mutual inductance between any two windings (i) and (j) in any machine can be easily computed from the following expression:

Each stator phase is assumed to be sinusoidally wound along the air gap and the squirrel-cage rotor is modelled as " $n$ " identical magnetically coupled circuits or loops (Munoz and Lipo, 2000). Each loop encompasses two adjacent rotor bars and the connection portions of the end rings between them. A detailed analysis for the inductance calculations is given in a previous paper (Allam et al. 2008).

\section{Dynamic Model In Qdo-AxesRotor Refer- ence Frame}

In order to eliminate the time-varying inductances in 
voltage equations, the machine was represented in the qdo- axes reference frame. The qdo-axes are fixed in the rotor, which rotates at the rotor speed $\left(\omega_{\mathrm{m}}\right)$. Figure 2 shows the phase axes relationship for phase "a" of any of the two stator windings axes and the nth-rotor loops axes.

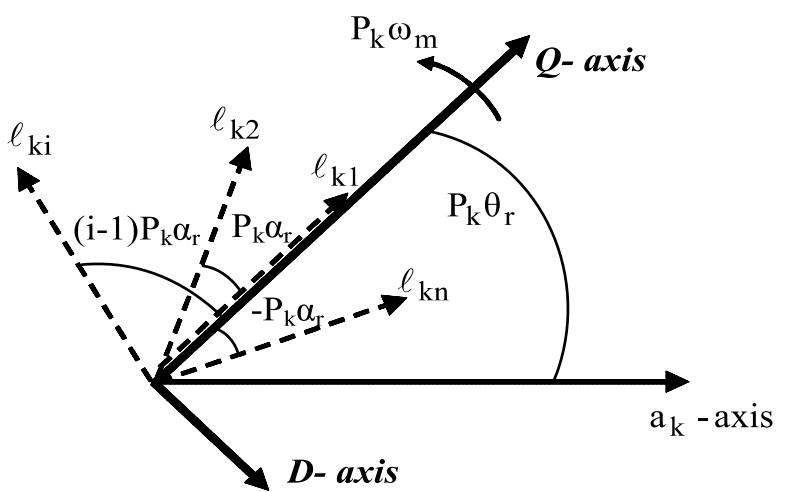

Figure 2. Phase axes relationship of the MDFIM

It should be noted that all equations used for the twostator windings are similar except for their different number of poles, turns per phase, resistance, and inductance. So, instead of writing theses equations twice, the subscript " $k$ " is used denoting either the power or the control windings. Hence, the same equation can be used to describe the two stator windings just by defining " $k$ " with suitable number related to each one of the two sets of stator windings.

The transformation matrix that transforms the $\mathrm{abc}_{\mathrm{k}}$-axis variables to either stator winding $\mathrm{qdo}_{\mathrm{k}}$-axis variables is given by:

$\left[F_{\mathrm{sk}}\right]=\frac{2}{3}\left[\begin{array}{ccc}\cos \left(\mathrm{P}_{\mathrm{k}} \theta_{\mathrm{r}}\right) & \cos \left(\mathrm{P}_{\mathrm{k}} \theta_{\mathrm{r}}-\frac{2 \pi}{3}\right) & \cos \left(\mathrm{P}_{\mathrm{k}} \theta_{\mathrm{r}}+\frac{2 \pi}{3}\right) \\ \sin \left(\mathrm{P}_{\mathrm{k}} \theta_{\mathrm{r}}\right) & \sin \left(\mathrm{P}_{\mathrm{k}} \theta_{\mathrm{r}}-\frac{2 \pi}{3}\right) & \sin \left(\mathrm{P}_{\mathrm{k}} \theta_{\mathrm{r}}+\frac{2 \pi}{3}\right) \\ \frac{1}{2} & \frac{1}{2} & \frac{1}{2}\end{array}\right]$

Where, $\theta_{\mathrm{r}=} \theta_{\mathrm{m}}+\delta, \delta=\alpha_{\mathrm{r}} / 2$ and $\delta_{\mathrm{r}}$ is the angle between two adjacent rotor bars.

The transformation matrix of either rotor circuits of nrotor loops axes to the corresponding $\mathrm{qdo}_{\mathrm{rk}}$-axis variables can be written based on Fig. 2 as:

$$
\left[\mathrm{F}_{\mathrm{rk}}\right]=\frac{2}{\mathrm{~m}}\left[\begin{array}{cccc}
\cos (0) & \cos \left(\mathrm{P}_{\mathrm{k}} \alpha_{\mathrm{r}}\right) & \cdots & \cos \left((\mathrm{n}-1) \mathrm{P}_{\mathrm{k}} \alpha_{\mathrm{r}}\right) \\
-\sin (0) & -\sin \left(\mathrm{P}_{\mathrm{k}} \alpha_{\mathrm{r}}\right) & \cdots & -\sin \left((\mathrm{n}-1) \mathrm{P}_{\mathrm{k}} \alpha_{\mathrm{r}}\right) \\
\frac{1}{2} & \frac{1}{2} & \cdots & \frac{1}{2}
\end{array}\right]
$$

It should be noted that, for a modified cage rotor, which is presented in this paper and due to the discontinuity of one of the two end rings, some rotor loops represent open loops. For the open loops at which the end ring is separated, the rotor loop current is set to zero and thus, the corresponding columns or elements are eliminated from the two matrices. The number of these columns equals the number of end ring sections (ie. summation of pole-pairs of both stator windings). This reduces the order of the matrices to be ' $3 * m$ ' instead of be ' $3 * n$ ', where ' $m$ ' is the total number of closed rotor loops (ie. difference between total number of rotor bars or loops and open loops at which the end ring is separated). Mathematically " $\mathrm{m}$ " can be given by:

$\mathrm{m}=\mathrm{n}-\Sigma \mathrm{P}_{\mathrm{k}}$, where $\Sigma \mathrm{P}_{\mathrm{k}}$ is the summation of the pole-pairs of the two stator windings.

\subsection{QDO-Axes Voltage Equations}

The final $\mathrm{qdo}_{\mathrm{k}}$-axes stator voltage equation can be written in a matrix form as:

$$
\begin{aligned}
& {\left[\mathrm{v}_{\mathrm{qdok}}\right]=\left[\mathrm{r}_{\mathrm{sk}}\right]\left[\mathrm{i}_{\mathrm{qdok}}\right]+\mathrm{p}\left[\lambda_{\mathrm{qdok}}\right]+\omega_{\mathrm{k}}\left[\lambda_{\mathrm{qdok}}\right]} \\
& {\left[\mathrm{r}_{\mathrm{sk}}\right]=\left[\begin{array}{ccc}
\mathrm{r}_{\mathrm{sk}} & 0 & 0 \\
0 & \mathrm{r}_{\mathrm{sk}} & 0 \\
0 & 0 & \mathrm{r}_{\mathrm{sk}}
\end{array}\right] \text {, and }\left[\omega_{\mathrm{k}}\right]=\mathrm{P}_{\mathrm{k}}\left[\begin{array}{ccc}
0 & \omega_{\mathrm{m}} & 0 \\
-\omega_{\mathrm{m}} & 0 & 0 \\
0 & 0 & 0
\end{array}\right]}
\end{aligned}
$$

Where:

It should be noted that the rotor can be modelled as two independent circuits. Each one has "n"-rotor loops and is related to one of the two stator windings with the same number of poles of the corresponding one. So, the subscript ' $\mathrm{k}$ ' may be also used to define the two different rotor circuits related to the corresponding two stator windings. This is attributed to the mutual decoupling of the two stator windings since they have different number of poles. Figure 3 shows a schematic diagram of n-rotor loops winding distribution for any of the corresponding two-stator windings just after defining ' $\mathrm{k}$ '. An open circuit rotor loop from one side of end rings is also shown in Fig. 3.

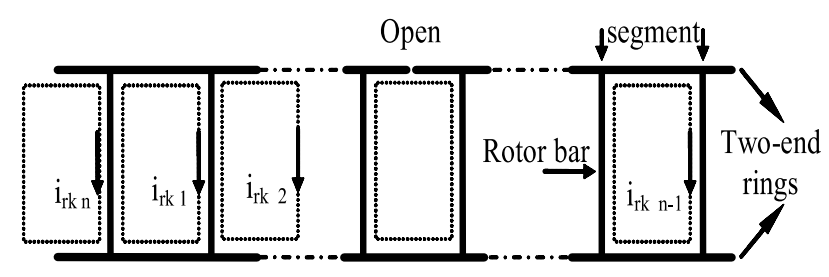

Figure 3. Rotor loops winding distribution

The final $\mathrm{qdo}_{\mathrm{rk}}$-axes rotor voltage equation can be written in a matrix form as:

$$
\begin{aligned}
& 0=\left[\mathrm{r}_{\text {qdo rk }}\right]\left[\mathrm{i}_{\text {qdo rk }}\right]+\mathrm{p}\left[\lambda_{\text {qdo rk }}\right] \\
& \text { Where: } \mathrm{r}_{\text {qdo rk }}=\left[\begin{array}{ccc}
\mathrm{r}_{\mathrm{rk}} & 0 & 0 \\
0 & \mathrm{r}_{\mathrm{rk}} & 0 \\
0 & 0 & \mathrm{r}_{\mathrm{or}}
\end{array}\right] \\
& \mathrm{r}_{\mathrm{rk}}=\mathrm{r}_{\ell}-2 \mathrm{r}_{\mathrm{b}}\left(1-\left(\sum \mathrm{P}_{\mathrm{k}} / \mathrm{m}\right)\right) \cos \left(\mathrm{P}_{\mathrm{k}} \alpha_{\mathrm{r}}\right) \\
& \mathrm{r}_{\text {or }}=\left(\mathrm{r}_{\ell}-2\left(1-\left(\sum \mathrm{P}_{\mathrm{k}} / \mathrm{m}\right)\right) \mathrm{r}_{\mathrm{b}}\right)
\end{aligned}
$$




\subsection{QDO-Axes Flux Linkage Relations}

Since the two stator windings are mutually decoupled, it should be noted that, in the flux linkage calculations, there is no component of flux linkage of any of the two stator windings or rotor circuits due to the current of the other one. Hence, the flux linkage in each of the stator windings or rotor circuits is established due to only two components. The first is due to the current in the same winding or circuit, and the second is due to the current of the corresponding one, which has the same number of poles. The total qdok-axes equation of the stator flux linkage can be written as:

$\lambda_{\text {qdok }}=\lambda_{\text {qdok qdok }}+\lambda_{\text {qdok qdork }}$

The $\mathrm{qdo}_{\mathrm{k}}$-axes stator flux linkage due to the corresponding $\mathrm{qdo}_{\mathrm{k}}$-axes stator winding current is given by:

$$
\left[\lambda_{\text {qdok }} \text { qdok }\right]=\left[\mathrm{L}_{\text {qdok }} \text { qdok }\right]\left[\mathrm{i}_{\text {qdok }}\right]
$$

Where:

$$
\begin{aligned}
& {\left[\mathrm{L}_{\text {qdok qdok }}\right]=\left[\begin{array}{ccc}
\mathrm{L}_{s \mathrm{k}} & 0 & 0 \\
0 & \mathrm{~L}_{s \mathrm{k}} & 0 \\
0 & 0 & \mathrm{~L}_{\ell \mathrm{k}}
\end{array}\right], \mathrm{L}_{\mathrm{sk}}=\mathrm{L}_{\ell \mathrm{k}}+\frac{3}{2} \mathrm{~L}_{\mathrm{mk}} \text {, and }} \\
& \mathrm{L}_{\mathrm{mk}}=\mu_{\mathrm{o}} \mathrm{R} \ell \mathrm{g}^{-1} \pi\left(\mathrm{N}_{\mathrm{k}} / 2 \mathrm{P}_{\mathrm{k}}\right)^{2}
\end{aligned}
$$

The $\mathrm{qdo}_{\mathrm{k}}$-axes stator flux linkage due to the corresponding $\mathrm{qdo}_{\mathrm{rk}}$-axes rotor current is given by:

$$
\left[\lambda_{\text {qdok qdork }}\right]=\left[\mathrm{L}_{\mathrm{m} \text { qdok qdork }}\right]\left[\mathrm{i}_{\text {qdo rk }}\right]
$$

where:

$$
\begin{aligned}
& {\left[\mathrm{L}_{\text {m qdok qdork }}\right]=\left[\begin{array}{ccc}
\mathrm{L}_{\mathrm{mkr}} & 0 & 0 \\
0 & \mathrm{~L}_{\mathrm{mkr}} & 0 \\
0 & 0 & 0
\end{array}\right]} \\
& \mathrm{L}_{\mathrm{mkr}}=(\mathrm{m} / 2) \mathrm{M}_{\mathrm{kr}} \text {, and } \mathrm{M}_{\mathrm{kr}}=\left(4 / \pi \mathrm{N}_{\mathrm{k}}\right) \sin \left(\mathrm{P}_{\mathrm{k}} \delta\right) \mathrm{L}_{\mathrm{mk}}
\end{aligned}
$$

The total $\mathrm{qdo}_{\mathrm{rk}}$-axes rotor flux linkage equation can be written as:

$\lambda_{\text {qdork }}=\lambda_{\text {qdork qdork }}+\lambda_{\text {qdork qdok }}$

The $\mathrm{qdo}_{\mathrm{rk}}$-axes rotor flux linkage due to the corresponding $\mathrm{qdo}_{\mathrm{rk}}$-axes rotor current is given by:

$$
\left[\lambda_{\text {qdork qdork }}\right]=\left[\mathrm{L}_{\text {qdo rk }}\right]\left[\mathrm{i}_{\text {qdork }}\right]
$$

Where: $\mathrm{L}_{\text {qdo rk }}=\left[\begin{array}{ccc}\mathrm{L}_{\mathrm{rk}} & 0 & 0 \\ 0 & \mathrm{~L}_{\mathrm{rk}} & 0 \\ 0 & 0 & \mathrm{~L}_{\text {or }}\end{array}\right]$

$\mathrm{L}_{\mathrm{rk}}=\mathrm{L}_{\ell \mathrm{r}}+\mathrm{L}_{\mathrm{mr}}-\mathrm{M}_{\mathrm{r}}-2 \mathrm{~L}_{\mathrm{b}}\left(1-\left(\sum \mathrm{P}_{\mathrm{k}} / \mathrm{m}\right)\right) \cos \left(\mathrm{P}_{\mathrm{k}} \alpha_{\mathrm{r}}\right)$

$\mathrm{L}_{\text {or }}=\mathrm{L}_{\ell \mathrm{r}}+\mathrm{L}_{\mathrm{mr}}+(\mathrm{m}-1) \mathrm{M}_{\mathrm{r}}-2\left(1-\left(\sum \mathrm{P}_{\mathrm{k}} / \mathrm{m}\right)\right) \mathrm{L}_{\mathrm{b}}$

The $\mathrm{qdo}_{\mathrm{rk}}$-axes rotor flux linkage due to the corresponding $\mathrm{qdo}_{\mathrm{k}}$-axes stator winding current is given by: $\left[\lambda_{\text {qdork qdok }}\right]=\left[\mathrm{L}_{\text {m qdork qdok }}\right]\left[\mathrm{i}_{\text {qdok }}\right]$

Where:

$$
\left[\mathrm{L}_{\text {m qdork qdok }}\right]=\left[\begin{array}{ccc}
\mathrm{L}_{\text {mrk }} & 0 & 0 \\
0 & \mathrm{~L}_{\text {mrk }} & 0 \\
0 & 0 & 0
\end{array}\right] \text {, and } \mathrm{L}_{\text {mrk }}=(3 / 2) \mathrm{M}_{\mathrm{kr}}
$$

The final form of qdo-axes system model in the rotor reference frame is given in the appendix.

\subsection{Electromagnetic Developed Torque Equation}

The electromagnetic developed torque of a BDFIM can be divided into two components. Each one is due to the mutual coupling between one of the two-stator windings and the corresponding rotor circuit. Thus, the total electromagnetic developed torque is given by the summation of these two components and can be written in terms of qdoaxis currents as:

$$
\mathrm{T}_{\mathrm{em}}=\Sigma \mathrm{T}_{\mathrm{emk}}=\mathrm{T}_{\mathrm{k} 1}+\mathrm{T}_{\mathrm{k} 2}
$$

Where:

$$
\begin{aligned}
& \mathrm{T}_{\mathrm{k} 1}=(3 / 2) \mathrm{L}_{\mathrm{mkr}} \mathrm{P}_{\mathrm{k}} \mathrm{i}_{\mathrm{qk}} \mathrm{i}_{\text {drk }} \\
& \mathrm{T}_{\mathrm{k} 2}=(-3 / 2) \mathrm{L}_{\mathrm{mkr}} \mathrm{P}_{\mathrm{k}} \mathrm{i}_{\mathrm{dk}} \mathrm{i}_{\mathrm{qrk}}
\end{aligned}
$$

\subsection{The Electromechanical Equation}

The electromechanical equation of a BDFIM can be easily written as:

$$
\mathrm{T}_{\mathrm{em}}=\mathrm{J} * \mathrm{p} \omega_{\mathrm{m}}+\mathrm{B}^{*} \omega_{\mathrm{m}}+\mathrm{T}_{\mathrm{L}}
$$

Equations (4) through (13) provide a useful dynamic representation of the machine. Thus, this model can be used to describe the dynamic performance of the machine in the qdo rotating axes.

\section{Steady-State Model}

\subsection{Steady-State Voltage Equations}

It is well known that the presented qdo-axes dynamic model is obtained in the rotor reference frame. Hence, in order to obtain the steady-state voltage equations, the differential operator " $\mathrm{p}$ " should be replaced by the rotor frequency, ie. $\mathrm{P}=\mathrm{J}\left(\omega_{\mathrm{ek}}-\mathrm{P}_{\mathrm{k}} \omega_{\mathrm{m}}\right)$. The final steady-state voltage equations for both the two stator windings and the corresponding two rotor circuits can be rewritten in a matrix form as:

$$
\left[\begin{array}{c}
\overline{\mathrm{v}}_{\mathrm{sk}} \\
0
\end{array}\right]=\left[\begin{array}{cc}
\mathrm{r}_{\mathrm{sk}}+\mathrm{j} \omega_{\mathrm{ek}} \mathrm{L}_{\mathrm{sk}} & \mathrm{j} \omega_{\mathrm{ek}} \mathrm{L}_{\mathrm{mkr}} \\
\mathrm{j} \omega_{\mathrm{ek}} \mathrm{L}_{\mathrm{mrk}} & \frac{\mathrm{r}_{\mathrm{rk}}}{\mathrm{s}_{\mathrm{k}}}+\mathrm{j} \omega_{\mathrm{ek}} \mathrm{L}_{\mathrm{rk}}
\end{array}\right]\left[\begin{array}{c}
\overline{\mathrm{i}}_{\mathrm{sk}} \\
\overline{\mathrm{i}}_{\mathrm{rk}}
\end{array}\right]
$$

Where 'sk' is the slip related to both stator windings and can be given by

$$
\mathrm{s}_{\mathrm{k}}=\frac{\omega_{\mathrm{ek}}-\mathrm{P}_{\mathrm{k}} \omega_{\mathrm{m}}}{\omega_{\mathrm{ek}}}
$$

Equation (14) has a similar form to the corresponding steady-state voltage equations of the conventional induc- 
tion machine. However, it can be observed that the term representing the mutual inductance between any of the two stator windings and the corresponding rotor circuits, $\mathrm{L}_{\mathrm{mkr}}$, is not the same as the mutual-inductance term between any of the two rotor circuits and the corresponding stator windings, $\mathrm{L}_{\text {mrk }}$. This case is not observed in the conventional induction machine. The reason is attributed to the representation of the rotor in the proposed BDFIM by an equally m-rotor loops or circuits, while the stator is represented by two equivalent three-phase circuits. However, in the conventional induction machine, equivalent three-phase circuits are used to represent both the stator and rotor.

\subsection{Steady-State Electromagnetic Torque Express- ion}

The steady-state electromagnetic torque developed by each one of the two stator windings can be expressed as:

$\mathrm{T}_{\mathrm{emk}}=3 \operatorname{Re}\left(\mathrm{jL} \mathrm{L}_{\mathrm{mkr}} \overline{\mathrm{i}}_{\mathrm{rk}} \overline{\mathrm{i}}_{\mathrm{sk}}^{*}\right)$

Or, it can be derived in another form as follows:

$$
\mathrm{T}_{\mathrm{emk}}=-m \operatorname{Re}\left(\begin{array}{lll}
\mathrm{j} \mathrm{L}_{\mathrm{mrk}} & \overline{\mathrm{i}}_{\mathrm{sk}} & \overline{\mathrm{i}}_{\mathrm{rk}}^{*}
\end{array}\right)
$$

Where, the acronym "Re" stands for "Real Part".

\section{Sample Case Studies}

Sample case studies are presented using the proposed model. The presented samples of the simulation results are obtained using Matlab/Simulink software with the calculated parameters of an actual set-up system. The stator and the rotor of a conventional three-phase squirrel-cage induction motor, rated at $1.1 \mathrm{~kW}, 460 \mathrm{~V}$ and 4-poles, are modified to fit the nature of BDFIM. One set of the two stator windings, the power windings, has six poles, while the other, the control windings, has two-poles. All mutual and magnetizing inductances are calculated using winding function method (Allam et al. 2008). Stator resistance and leakage inductance are measured using standard techniques that used for the conventional induction machines. Dimensions of both rotor bar and end-ring are used to calculate their resistance and leakage inductance.

Experimentally, in studying the performance of the BDFIM under different operating conditions, the six-poles power windings are connected to a constant voltage constant frequency supply. On the other hand, the two-poles control windings are connected to an inverter operating in a constant voltage per hertz (V/f) mode (ie. doubly-fed operation) or left open (ie. singly-fed operation).

\subsection{Singly-Fed Operation}

Figure V4 shows the run-up response of a singly-fed mode of the BDFIM. In this mode of operation, the power windings are connected directly to the mains supply, while the control windings are left open under no-load condi- tion. The power windings are connected in a star configuration, where the mains supply is set to 100 -Volt (line-line voltage) with a frequency of $50-\mathrm{Hz}$. To simulate the case of open circuit in the control windings, a very high resistor is connected to its terminals.

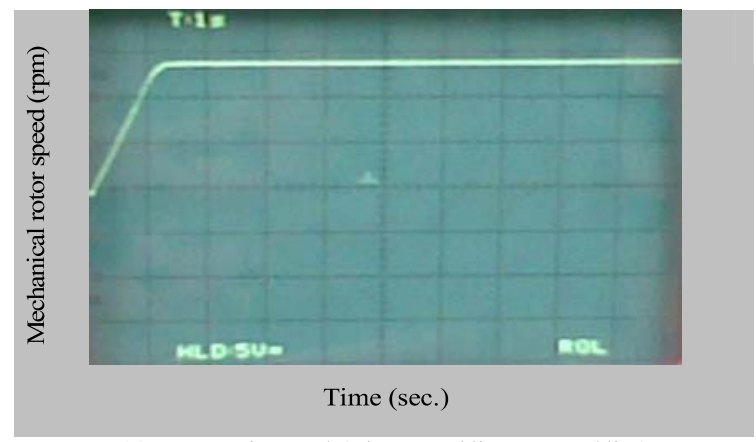

(a) Experimental $(5 * 70 \mathrm{rpm} /$ div \& $1 \mathrm{sec} . /$ div. $)$

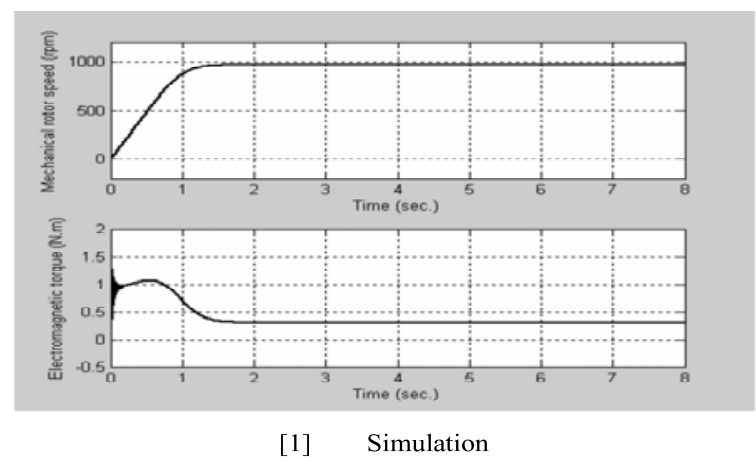

Figure V.4. Run-up response of a singly-fed mode of the BDFIM under no-load conditions

It can be noted that, the machine gives a response similar to that of the conventional 6-pole induction machine, where the motor runs up to a steady-state speed that is close to the synchronous speed, ie. 1000-rpm. The predicted 6-pole electromagnetic torque during free acceleration is also shown in the figure. The similarity between simulated and experimental results confirms that the proposed model is valid to describe the transient behaviour of the conventional induction machine operating only with one set of three-phase stator windings.

\subsection{Doubly-Fed Operation}

For more understanding of the machine behavior, the BDFIM is examined in a doubly-fed mode under different modes of operations in a sequential manner. Figure V.5 shows the run-up response of a doubly-fed mode of the BDFIM followed by two different operating conditions. In the simulation process, the power winding is firstly connected directly to the mains supply while the control winding is left open under no-load condition up to $4.0 \mathrm{sec}-$ onds, when a 0.25 N.m load torque is applied. Then, the control winding is connected to the mains supply via an inverter after 4.0 seconds from the loading time (ie. 8.0 seconds from starting). The power windings and the control windings are connected in star configuration.

Experimentally, the voltage of the mains power supply is set to 100 -Volt (line-line voltage) with a frequency of $50-\mathrm{Hz}$. On the other hand, the control-winding inverter is 
operated in a constant voltage per hertz mode $(220 / 50$ $\mathrm{V} / \mathrm{Hz}$ ) and the output control frequency is set to $10 \mathrm{~Hz}$. The control winding is excited with a reversed sequence with respect to the power-winding sequence. The predicted electromagnetic torque is also shown in Fig. V.5. It can be observed from the figure that, the effect of inserting the control winding with a reversed sequence excitation is to reduce the steady-state operating speed.

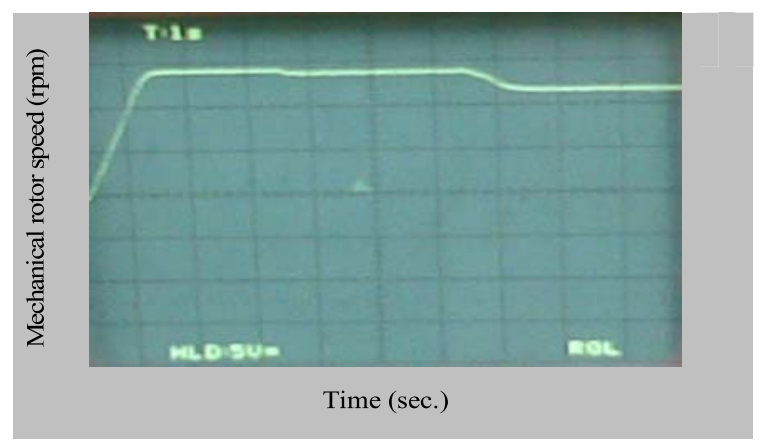

(a) Experimental $(5 * 70 \mathrm{rpm} / \mathrm{div} \& 1 \mathrm{sec} . / \mathrm{div}$.)

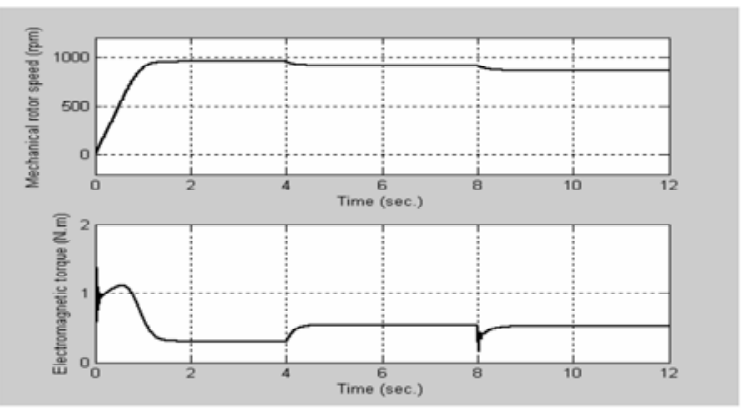

(a) Simulation

Figure V.5. Run-up response of a doubly-fed mode of a loaded MDFIM with a control frequcy of $10 \mathrm{~Hz}$

\subsection{Steady-State Characteristics}

To highlight the steady-state performance, Fig. 6 represents the simulated and experimental speed as a function of the control winding frequency at constant load torque. The power windings are connected in a star configuration,

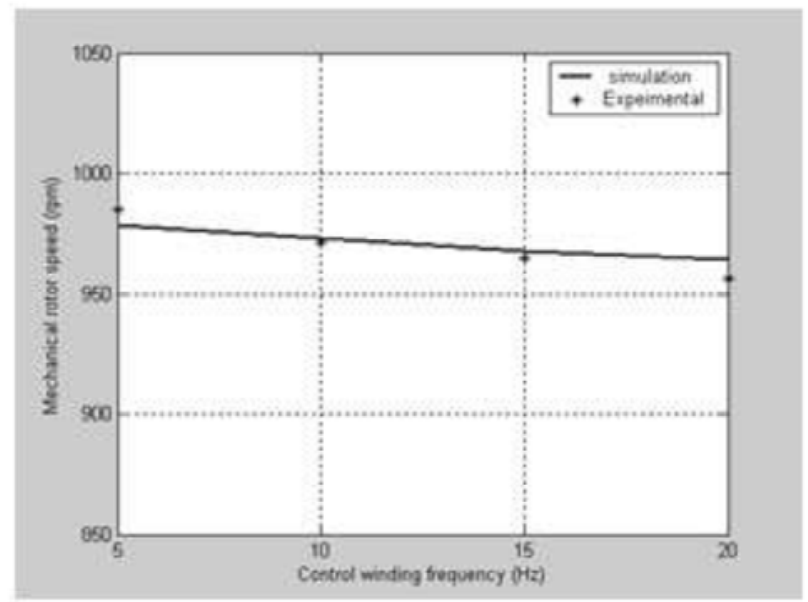

Figure 6. Speed/Frequency variation of a BDFIM Reversed Sequence)

where the mains supply is set to 150 -Volt (line-line voltage) with a frequency of $50-\mathrm{Hz}$. The control winding is excited with the reverse sequence of the power winding. It is clear from the figure that the speed control through the frequency of the control winding is possible. The range of the speed variation can be increased with proper voltage and frequency control of the control winding.

\section{Conclusions}

This paper has presented an accurate analysis that is valid for predicting the dynamic and steady-state performance of brushless doubly-fed induction machines. A general model in the qdo-axes has been derived from the basic relations of the machine. The winding function method is used as a viable method for calculating the machine inductances. In addition, a corresponding steady state model is derived using appropriate relations. In order to confirm the validity of the proposed model, Sample case studies have been introduced using actual experimental set-up parameters. The agreement between simulated and experimental results ensures the validity and effectiveness of the proposed model.

\section{References}

Allam, S.M., Azmy, A.M., Khater, M.M. and ElKhazendar, M.A., 2008, "A Generalized Dynamic Model for Brushless Doubly-fed Induction Machines," Engineering Research Journal (ERJ), Vol. 31(4), pp. 345- 54, Minoufiya University, Faculty of Engineering, Shebin El-Kom, Egypt, ISSN 1110-118.

Boger, M.S. and Wallace, A.K., 1995, "Performance Capability Analysis of the Brushless Doubly-fed Machine as a Wind Generator," Seventh International Conference on Electrical Machines and Drives, (Conf. Publ. No. 412), pp. 458-461.

Boger, M.S., Wallace, A.K., Spee, R. and Li, R., 1996, "Investigation of Appropriate Pole Number Combinations for Brushless Doubly-fed Machines Applied to Pump Drives," IEEE Transactions on Industry Applications, Vol. 32(1), pp. 189-194.

Boger, M.S., Wallace, A.K., Spee, R. and Li, R., 1995, "General Pole Number Model of the Brushless Doubly-fed Machine," IEEE Transactions on Industry Applications, Vol. 31(5), pp. 1022-1028.

Li, R., Wallace, A.K., Spee, R. and Wang, Y., 1991, "Two-axis Model Development of Cage-rotor Brushless Doubly-fed Machines," IEEE Transactions on Energy Conversion, Vol. 6(3), pp. 453-460.

Liang, F., Xu, L. and Lipo, T.A., 1991, "d-q Analysis of a Variable Speed Doubly ac Excited Reluctance Motor," Electrical Machines and Power Systems, Vol. 19(2), pp. 125-138.

Munoz, A.R. and Lipo, T.A. 2000, "Dual Stator Winding Induction Machine Drive," IEEE Transactions on Industry Applications," Vol. 36(5), pp. 1369-1379.

Wang, F., Zhang, F. and Xu, L., 2002, "Parameter and Performance Comparison of Doubly-fed Brushless Machines with Cage and Reluctance Rotors," IEEE 
Transactions on Industry Applications, Vol. 38(5), pp. 1237-1243.

Williamson, S., Ferreira, A.C. and Wallace, A.K., 1997, "Generalized Theory of the Brushless Doubly-fed Machine. Part 1: Analysis," IEE Proc.-Electr. Power Appl., Vol. 144(2), pp. 111-122.

Xu, L., Liang, F. and Lipo, T.A., 1991, "Transient Model of a Doubly Excited Reluctance Motor," IEEE
Transactions on Energy Conversion, Vol. 6(1), pp. 126-133.

Zaiping, P., Yanfeng, Z. and Nagrial, M.H., 1998, "Review and Future Application of Brushless Doubly-fed Machine," The 1998 International Conference on Communication, Computer \& Power, pp. 306-311. 
The Journal of Engineering Research Vol. 7 No. 2 (2010) 1-9

\section{Appendix}

A. Final form of qdo-axes system model in rotor reference frame

$$
\left[\begin{array}{c}
\mathrm{v}_{\mathrm{qk}} \\
\mathrm{v}_{\mathrm{dk}} \\
\mathrm{v}_{\mathrm{ok}} \\
\mathrm{v}_{\mathrm{qrk}} \\
\mathrm{v}_{\mathrm{drk}} \\
\mathrm{v}_{\text {ork }}
\end{array}\right]=\left[\begin{array}{cccccc}
\mathrm{r}_{\mathrm{sk}}+\mathrm{L}_{\mathrm{sk}} \mathrm{p} & \mathrm{P}_{\mathrm{k}} \omega_{\mathrm{m}} \mathrm{L}_{\mathrm{sk}} & 0 & \mathrm{~L}_{\mathrm{mkr}} \mathrm{p} & \mathrm{P}_{\mathrm{k}} \omega_{\mathrm{m}} \mathrm{L}_{\mathrm{mkr}} & 0 \\
-\mathrm{P}_{\mathrm{k}} \omega_{\mathrm{m}} \mathrm{L}_{\mathrm{sk}} & \mathrm{r}_{\mathrm{sk}}+\mathrm{L}_{\mathrm{sk}} \mathrm{p} & 0 & -\mathrm{P}_{\mathrm{k}} \omega_{\mathrm{m}} \mathrm{L}_{\mathrm{mkr}} & \mathrm{L}_{\mathrm{mkr}} \mathrm{p} & 0 \\
0 & 0 & \mathrm{r}_{\mathrm{sk}}+\mathrm{L}_{\ell \mathrm{k}} \mathrm{p} & 0 & 0 & 0 \\
\mathrm{~L}_{\mathrm{mrk}} \mathrm{p} & 0 & 0 & \mathrm{r}_{\mathrm{rk}}+\mathrm{L}_{\mathrm{rk}} \mathrm{p} & 0 & 0 \\
0 & \mathrm{~L}_{\mathrm{mrk}} \mathrm{p} & 0 & 0 & \mathrm{r}_{\mathrm{rk}}+\mathrm{L}_{\mathrm{rk}} \mathrm{p} & 0 \\
0 & 0 & 0 & 0 & 0 & \mathrm{r}_{\text {or }}+\mathrm{L}_{\text {ork }} \mathrm{p}
\end{array}\right]\left[\begin{array}{c}
\mathrm{i}_{\mathrm{qk}} \\
\mathrm{i}_{\mathrm{dk}} \\
\mathrm{i}_{\text {ok }} \\
\mathrm{i}_{\mathrm{qrk}} \\
\mathrm{i}_{\text {drk }} \\
\mathrm{i}_{\text {ork }}
\end{array}\right]
$$

